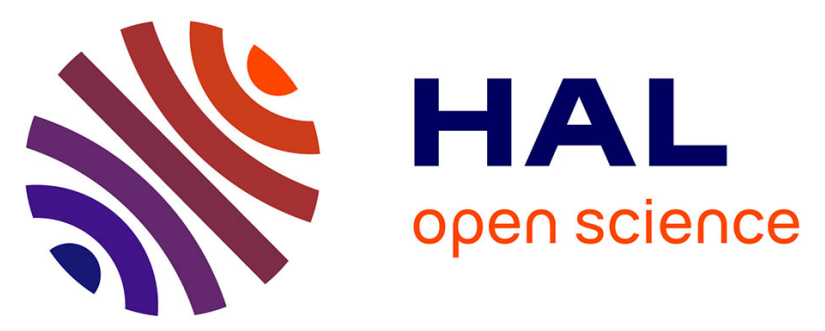

\title{
Urinary pesticide concentrations in French adults with low and high organic food consumption: results from the general population-based NutriNet-Santé
}

Julia Baudry, Laurent Debrauwer, Gaël Durand, Gwendolina Limon, Adéline Delcambre, Rodolphe Vidal, Bruno Taupier-Letage, Nathalie Druesne-Pecollo, Pilar Galan, Serge Hercberg, et al.

\section{To cite this version:}

Julia Baudry, Laurent Debrauwer, Gaël Durand, Gwendolina Limon, Adéline Delcambre, et al.. Urinary pesticide concentrations in French adults with low and high organic food consumption: results from the general population-based NutriNet-Santé. Journal of Exposure Science and Environmental Epidemiology, 2019, 29 (3), pp.366-378. 10.1038/s41370-018-0062-9 . hal-02120094

\section{HAL Id: hal-02120094 \\ https://hal-amu.archives-ouvertes.fr/hal-02120094}

Submitted on 5 May 2019

HAL is a multi-disciplinary open access archive for the deposit and dissemination of scientific research documents, whether they are published or not. The documents may come from teaching and research institutions in France or abroad, or from public or private research centers.
L'archive ouverte pluridisciplinaire HAL, est destinée au dépôt et à la diffusion de documents scientifiques de niveau recherche, publiés ou non, émanant des établissements d'enseignement et de recherche français ou étrangers, des laboratoires publics ou privés. 
Urinary pesticide concentrations in French adults with low and high organic food consumption: results from the general population-based NutriNet-Santé

Julia Baudry $^{\mathrm{a}^{*}} \mathrm{PhD}$, Laurent Debrauwer ${ }^{\mathrm{b}} \mathrm{PhD}$, Gaël Durand ${ }^{\mathrm{c}} \mathrm{PhD}$, Gwendolina Limon ${ }^{\mathrm{c}} \mathrm{MSc}$, Adéline Delcambre ${ }^{\mathrm{b}} \mathrm{PhD}$, Rodolphe Vidal ${ }^{\mathrm{d}} \mathrm{MSc}$, Bruno Taupier-Letage ${ }^{\mathrm{d}} \mathrm{MSc}$, Nathalie Druesne-Pecollo ${ }^{\mathrm{a}} \mathrm{PhD}$, Pilar Galan ${ }^{\mathrm{a}} \mathrm{PhD}$ MD, Serge Hercberg ${ }^{\mathrm{a}, \mathrm{e}}$ Prof, Denis Lairon ${ }^{\mathrm{f}} \mathrm{PhD}$, Jean-Pierre Cravedi ${ }^{\mathrm{b}} \mathrm{PhD}$, Emmanuelle Kesse-Guyot ${ }^{\mathrm{a}} \mathrm{PhD}$

${ }^{a}$ Equipe de Recherche en Epidémiologie Nutritionnelle (EREN), Université Paris 13, Inserm (U1153), Inra (U1125), Centre d'Epidémiologie et Statistiques Sorbonne Paris Cité, Cnam, COMUE SorbonneParis-Cité, F-93017 Bobigny, France ;

${ }^{\mathrm{b}}$ Toxalim, Université de Toulouse, INRA, ENVT, INP-Purpan, UPS, F-31027 Toulouse, France ;

${ }^{c}$ LABOCEA, F-29280 Plouzané France ;

${ }^{\mathrm{d}}$ Institut Technique de l'Agriculture Biologique (ITAB), F- 75595 Paris, France ;

e Département de Santé Publique, Hôpital Avicenne, F-93017 Bobigny, France ;

${ }^{\mathrm{f}}$ Aix Marseille Université, INSERM, INRA, C2VN, 13005 Marseille, France

*Correspondence: Email: j.baudry@eren.smbh.univ-paris13.fr

Equipe de Recherche en Epidémiologie Nutritionnelle (EREN)

SMBH Université Paris 13

74 rue Marcel Cachin, 93017 Bobigny, France

Running title: pesticide exposure and organic consumption 


\section{Abstract}

2 An organic diet may reduce dietary exposure to pesticides but findings based on observational data are

3 scant. We aimed to compare urinary pesticide concentrations between "organic" and "conventional"

4 consumers from the NutriNet-Santé study. Organic food consumption was determined using a self-

5 reported food frequency questionnaire. Individuals with a proportion of organic food in the whole diet

6 (in $\mathrm{g} / \mathrm{d}$ ) below $10 \%$ were defined as low organic food consumers and those whose proportion was

7 above $50 \%$ as high organic food consumers. A propensity score matching procedure was then used to

8 obtain two similar subsets of 150 participants, differing mostly by the organic valence of their diet.

9 Urinary pesticide and metabolite concentrations (organophosphorus, pyrethroid and azole compounds)

10 were determined by UPLC-MS/MS, standardized with respect to creatinine. The molar sums of total

11 diethylphosphates, dimethylphosphates and dialkylphosphates were also computed. Differences in

12 distributions across groups were tested using Wilcoxon signed-rank test for matched data. Mean age

13 was $58.5 \mathrm{y}$ and $70 \%$ of participants were women. Significantly lower urinary levels of

14 diethylthiophosphate, dimethylthiophosphate, dialkylphosphates and free 3-phenoxybenzoic acid were

15 observed among organic consumers compared to conventional consumers. Our findings confirm that

16 exposure to certain organophosphate and pyrethroïd pesticides in adults may be lowered by switching

17 from conventional to organic foods. This is particularly of high interest among conventional fruit and

18 vegetables consumers, as their exposure may be the highest.

19 Keywords: dietary exposure; epidemiology; pesticides 


\section{Introduction}

Pesticides are widely used to protect crops against harmful organisms and diseases but are also utilized as biocides for non-agricultural purposes. Despite these beneficial aspects, there has been an increasing concern during the last decade that these compounds represent a risk to the general population through residues in food commodities. The toxicological outcomes that have been associated with pesticide exposure include neurological, respiratory, dermatological, digestive, carcinogenic, reproductive and developmental effects, as recently reviewed by several authors ${ }^{1-3}$. Five pesticides (malathion, glyphosate, parathion, diazinon and tetrachlorvinphos) were classified as probably carcinogenic to humans by the International Agency for Research on Cancer ${ }^{4}$. In addition, a high number of agrochemicals have been documented to affect the endocrine system ${ }^{5,6}$, causing reproductive and developmental adverse effects, but also resulting in metabolic disorders ${ }^{7,8}$. Knowledge on the consequences of exposure levels observed in the general population remains scarce and difficult to interpret ${ }^{9}$. France is one of the largest users in tons of agricultural pesticides in the European Union ${ }^{10}$. Routes of exposure to pesticides are multiple (oral, dermal and respiratory) but diet is the main source of pesticide exposure in the general population ${ }^{11}$. It is therefore essential to estimate how and to what extent, different dietary consumption patterns - from more or less contaminated food sources (e.g. organically vs. conventionally grown products) may affect exposure.

Organic production and labelling of organic products are held under legal framework of the Council Regulation (EC) No 834/2007, which limits the use of pesticides to a small number (i.e. 35) of natural substances while 488 active substances are approved by (EC) No 1107/2009 as pesticides in conventional agriculture in the European Union ${ }^{12}$. This exclusion of synthetic pesticides results in a significantly lower frequency of (or no) contamination in organic foods when compared to conventional foods, as consistently described in food residue analyses ${ }^{13-16}$. Some experimental studies, using mostly cross-over design, have been carried out among children ${ }^{17-19}$ and adults ${ }^{20,21}$, and all report that the adoption of a diet mainly based on organic foods leads to a significant reduction in pesticide levels in urine (including organophophate pesticides and herbicide 2,4-D ${ }^{17-21}$ ). Furthermore, the considerable recent growth of organic food market ${ }^{22}$ is largely due to consumers' concerns for food safety. Indeed, organic products are perceived healthier by consumers than conventional ones 
mainly because of their absence of pesticide residues ${ }^{23-27}$. Yet the extent to which day-life high organic food consumption is related to reduced urinary pesticide concentrations, more specifically in European adults, is not well documented.

In this context, the objective of the current study was to test for differences in pesticide exposure, reflected by urinary biomarkers, among adults with low and high self-reported organic food consumption.

\section{Methods}

\section{Study population}

The NutriNet-Santé study is an ongoing web-based observational prospective study launched in France in May 2009 on a large sample of adult volunteers. Its general aim is to investigate the relationships between dietary patterns, nutrition and health issues ${ }^{28}$. Participants over age of $18 \mathrm{y}$ are recruited among the general population by means of vast multimedia campaigns. All questionnaires are completed online using a dedicated website.

The NutriNet-Santé study is conducted according to the Declaration of Helsinki guidelines and was approved by the Institutional Review Board of the French Institute for Health and Medical Research (IRB Inserm $n^{\circ} 0000388 \mathrm{FWA00005831)}$ and the "Commission Nationale de l'Informatique et des Libertés" (CNIL nº08450/n909216). Clinicaltrials.gov number: NCT03335644.

On a voluntary basis, participants were also invited to attend health centers for biological sampling and clinical examination (2011-2013). During the visit, volunteers underwent blood and urine sampling as well as a clinical examination including anthropometric measurements. Overall, samples of serum, plasma, buffy-coats and urine were set up for about 20,000 participants of the cohort ${ }^{29}$. Electronic and paper written informed consents were obtained from all subjects attending the visit. All procedures were approved by the Consultation Committee for the Protection of Participants in Biomedical Research" (C09-42 on May 5th 2010) and the CNIL (n $\left.{ }^{\circ} 460707\right)$.

\section{Sociodemographic, anthropometric and biological data}


To be included in the cohort, participants have to fill in a set of questionnaires providing information on sociodemographic (age, sex, educational level, employment status, place of residence) and lifestyle (smoking status, physical activity) characteristics and health data (menopausal status for women, medical history and medication). Every year thereafter, as part of their follow-up, they are also invited to complete this same set of questionnaires to update their information.

During the clinical visits, systolic and diastolic blood pressure, weight and height were measured using standardized procedures ${ }^{30}$. Fasting blood glucose, total serum cholesterol, HDL-cholesterol and serum triglycerides were routinely measured as previously described ${ }^{29}$.

\section{Assessment of total and organic food consumption}

Total and organic food consumptions were assessed using an organic semi-quantitative food frequency questionnaire (Org-FFQ). In June 2014, NutriNet-Santé participants were invited to complete the OrgFFQ through the dedicated secured website. The development of the Org-FFQ has been fully described elsewhere ${ }^{31}$. Briefly, the Org-FFQ consisted of 264 food and beverage items. It was based on a validated FFQ ${ }^{32}$, completed by specific questions about organic food consumption frequency. Briefly, for each of the 264 items subjects were asked to report their frequency of consumption and the quantity consumed over the past year. Additionally, a five-point Likert-type scale ranging from never to always was used to estimate the frequency of organic food consumption of each food item. Organic food intake was obtained for each item by applying a weight of $0,0.25,0.5,0.75$ and 1 to the five respective categories of frequency (never, rarely, half of the time, often and always). Using the OrgFFQ, the proportion of organic food in the whole diet $(\mathrm{g} / \mathrm{d})$ was then calculated by dividing the total organic food consumption out of the total food consumption excluding water. Participants were also invited to fill in a questionnaire pertaining to motivations and attitudes towards organic foods.

\section{Selection of the subsample and matching procedure}

Of the 33,384 subjects who had completed the Org-FFQ, we selected those with available data regarding total and organic food consumption, with no missing covariates and who had attended the clinical visits $(\mathrm{N}=5,746)$. Among them, we selected subjects who had fasted at least 6 hours before the 
visit and subjects who were no subject to potential metabolic disorders, i.e. subjects with no history of type I diabetes, Crohn's disease, all types of cancer, neurological diseases, cardiovascular diseases, digestive system diseases (including cirrhosis, hepatitis, celiac disease and colitis) lupus, spondylolisthesis and sclerosis $(\mathrm{N}=4,598)$ (Figure 1). Then low and high organic food consumers were identified as those with a proportion of organic food in the whole diet $(\mathrm{g} / \mathrm{d})$ below $10 \%$ or above $50 \%$, respectively $(\mathrm{N}=2,351)$. Finally, in order to account for profile differences between low and high organic food consumers, we applied a propensity score matching procedure without replacement. This matching approach, based on a single composite score, enabled to achieve comparability between the two groups in terms of their observed characteristics ${ }^{33}$. We thus obtained two propensity scorematched groups of 150 subjects, differing by the organic valence of their diet. Selection and matching procedures are extensively described in the Supplemental Material.

\section{Urine collection, creatinine and pesticide analysis}

At the clinical visit, urine sample collection was performed using vessels allowing the close-circuit urine transfer from the vessel to the Vacutainer ${ }^{\circledR}$ tube. The Vacutainer ${ }^{\circledR}$ tubes containing the spot urine sample were kept at $+4^{\circ} \mathrm{C}$ before and during transportation to the central laboratory. After splitting in aliquots, urine samples were stored at $-80^{\circ} \mathrm{C}$ for further analyses. To account for urine dilution, creatinine concentration $(\mu \mathrm{g} / \mathrm{L})$ was used to adjust analyte concentrations. Urinary creatinine concentration was determined by ${ }^{1} \mathrm{H}$ NMR according to a method adapted from Bouatra et al. ${ }^{34}$. All pesticide assays were performed in the same laboratory. The final list of analyzed pesticides and metabolites has been defined as a compromise between scientific objectives, financial cost and the available measurement methods. The extraction method for Group 1 (dimethylphosphate (DMP), dimethylthiophosphate (DMTP), dimethyldithiophosphate (DMDTP), diethylphosphate (DEP), diethylthiophosphate (DETP), diethyldithiophosphate (DEDTP)) was 96-well $\mu$ Elution Solid Phase Extraction-off line, Oasis Wax well Plate, $30 \mu \mathrm{m}, 2 \mathrm{mg}$, Waters (Milford, Massachusetts, USA) for purification and concentration purposes. The sample volume used was $200 \mu$, diluted by $200 \mu 1$ of water $4 \%$ formic acid. The compounds were eluted using a 5\% ammonium hydroxide solution in acetonitrile. The extraction for other analytes - Group 2 (chlorpyrifos and metabolites, malathion, 
131 dichlorvos, phoxim, diazinon, thiabendazole-5-OH (TBZ-OH), tebuconazole, 2-(diethylamino)-6132 methylpyrimidin-4-ol/one (DEAMP) (pyrimiphos methyl metabolite), pyrethroid metabolites (3133 phenoxybenzoic acid (3-PBA), 4-fluoro-3-phenoxybenzoic acid (4-FPBA)) and 3,5,6134 trichloropyridinol (TCP)) was performed with Solid Phase Extraction-off line, Oasis HLB well Plate, $13530 \mu \mathrm{m}, 2 \mathrm{mg}$, Waters (Milford, Massachusetts, USA). The sample volume used was $250 \mu$, diluted by $136250 \mu 1$ of water $4 \%$ ammonium hydroxide. The elution was done using a methanol-acetonitrile 137 solution acidified with formic acid $(0.05 \%)$.

138 A second analysis was performed for the deconjugated compounds before the same protocol of 139 extraction: an enzymatic hydrolysis was performed, on $250 \mu 1$ sample, for total (free and conjugated) 140 TBZ-OH, tebuconazole, DEAMP, pyrethroid metabolites (3-PBA et 4-FPBA) and TCP, using $\beta$ 141 Glucuronidase / Arylsulfatase (Helix pomatia) from Roche (Mannheim, Germany), after stabilization 142 with sodium acetate buffer solution, $\mathrm{pH}$ 4.5-5.5, as described by the supplier (Sigma-Aldrich, Seelze, 143 Germany), during 16 hours. at $37^{\circ} \mathrm{C}$.

144 Analyses of pesticides and metabolites (for correspondence between metabolites and parent 145 compounds, see Supplemental Table 1) were performed using UPLC H-Class system coupled with a 146 tandem mass spectrometry Xevo TQ-S (UPLC-MSMS) (Waters, Milford, USA).

147 For the pesticides from Group 1, a volume of $15 \mu 1$ was injected in a column BEH amide $1.7 \mu \mathrm{m} 2.1 \mathrm{x}$ $148100 \mathrm{~mm}$ (Waters, Milford, USA) in an oven at $35^{\circ} \mathrm{C}$. The eluents used were water $50 \mathrm{mM}$ ammonium 149 acetate / acetonitrile with a gradient from $90 \%$ to $20 \%$ acetonitrile, with a flow rate of $0,4 \mathrm{ml} / \mathrm{min}$. The 150 analysis was performed in ES-mode. For the pesticides from Group 2, a volume of $10 \mu 1$ was injected 151 in a column BEH C18 $1.7 \mu \mathrm{m} 2.1 \times 100 \mathrm{~mm}$ (Waters, Milford, USA). The eluents used were 152 water/acetonitrile $+0.05 \%$ formic acid with a gradient from. $85.5 \%$ to $2 \%$ water, in an oven at $40{ }^{\circ} \mathrm{C}$ 153 temperature with a flow rate of $0.4 \mathrm{ml} / \mathrm{min}$ The analysis was performed in ES + and ES- mode.

Quality control/quality assurance

156 All standards used were certified standards provided by Sigma-Aldrich (Seelze, Germany), A2S (St 157 Jean d'Illac, France) and Dr Ehrenstorfer (Augsburg, Germany). 
158 A set of five calibrations in the range 0.01 to $10 \mu \mathrm{g} / \mathrm{L}$ for samples of human urine free of the target 159 biomarkers was analyzed each day for 5 days for inter-assay precision and accuracy. For intra-assay 160 precision and accuracy, three levels of concentrations (near limit of quantification, average and high 161 level) were analyzed in different human urine free of the target biomarkers ten times. A weighted 162 linear regression model $(1 / \mathrm{x})$ was used for the construction of calibration curve. Throughout the study a quality control was analyzed every ten samples and a blank every twenty samples. Dichlorvos-D6, chlorpyrifos-methyl-D6, chlorpyrifos-D10, malathion-D6, diazinon-D10, DETP-D10 and DMTP-D6 served as internal standards.

The limit of detections (LODs) ranged from 0.003 to $0.6 \mu \mathrm{g} / \mathrm{L}$. The limit of quantification (LOQs) ranged from 0.01 to $2 \mu \mathrm{g} / \mathrm{L}$ with a coefficient of variation ranging from 10 to $25 \%$. LODs were 3 fold higher the intensity of the background noise and LOQs were, overall, 3 fold higher than LODs.

\section{Statistical analysis}

171 For comparative purposes and as previously done in other publications ${ }^{18,21}$, we calculated the following molar sums $(\mu \mathrm{mol} / \mathrm{g})$, based on concentration of individual organophosphorus metabolites ( $\mu \mathrm{g} / \mathrm{g}$ creatinine) and molecular weights $(\mathrm{g} / \mathrm{mol})$ :

$$
\begin{gathered}
\text { total MPs }=\frac{[D M P]}{125}+\frac{[D M T P]}{141}+\frac{[D M D T P]}{157} \\
\text { total EPs }=\frac{[D E P]}{153}+\frac{[D E T P]}{169}+\frac{[D E D T P]}{186} \\
\text { total DAPs }=\text { total MPs }+ \text { total EPs }
\end{gathered}
$$

174 with DMP, dimethylphosphate ; DMTP, dimethylthiophosphate ; DMDTP, dimethyldithiophosphate ;

175 DEP, diethylphosphate ; DETP, diethylthiophosphate ; DEDTP, diethyldithiophosphate ; DAPs, 176 dialkylphosphates; MPs, dimethylphosphates; EPs, diethylphosphates.

177 Samples containing concentrations below the LOD (limit of detection) were assumed to have 178 concentrations equal to $1 / 2$ LOD. Samples containing concentrations below the LOQ (limit of 179 quantification) were assumed to have a concentration equal to the midpoint between the LOD and the 180 LOQ $^{35}$. 
181 We performed a balance diagnostic of the matching procedure to obtain standardized differences for

182 variables included in the propensity score model as recommended ${ }^{33}$, using the SAS macro \%pmdiag

$183 \quad$ 33. Characteristics of the participants are presented by group of consumers and were compared using

184 Wilcoxon signed-rank test for matched samples for continuous variables and McNemar test (binary 185 variables) or conditional logistic regression for categorical variables (>2-class variables). We 186 computed the modified Programme National Nutrition Santé Guideline Score (mPNNS-GS), an $a$ 187 priori nutritional index reflecting the adherence to the French food-based nutritional guidelines ${ }^{36}$. A 188 higher score $(\max =13.5)$ reflects a higher nutritional quality of the diet ${ }^{37}$. Distribution indicators, 189 frequency of detection and of quantification are provided.

190 Additionally, in a sensitivity analysis, in order to increase the discriminating power of our analyses, 191 we only considered subjects with proportion of organic food in the diet below $5 \%$ for the conventional 192 group and their matching organic pairs $(n=218)$. All analyses were performed using 9.4 version of the 193 SAS software (SAS Institute Inc., Cary, NC, USA).

\section{Results}

The balance diagnostic of the matching procedure is presented in Supplemental Table 2. The vast majority of the variables including health, sociodemographic and diet displayed similar distributions across organic and conventional groups, except for consumption of mixed dishes ( $\mathrm{p}$-value $<0.05$ ). Participants' characteristics are shown in Table 1. The average proportions of organic food in the diet were $3 \%( \pm 3)$ and $67 \%( \pm 13)$ in the conventional and organic groups, respectively. Diet quality, assessed using the mPNNS-GS, was relatively high. Mean age participants was $58 \mathrm{y}$, about $30 \%$ of the participants were men and more than $60 \%$ were highly educated.

Levels of exposure to pesticides through urinary parent moieties and metabolites are presented in Tables 2 and 3. Parent pesticides were detectable in a limited number of samples in the two groups ( $\max =9 \%$ for malathion in the conventional group). Mean and median molecule concentrations were mostly below the LOD (Table 2). In contrast, for some metabolites such as total DEAMP, total TBZ$\mathrm{OH}$, total tebuconazole, most EPs and MPs (except DEDTP and DMDTP) and free 3-PBA, the 
(Table 3). The mean concentrations of DETP, DMTP and free 3-PBA were significantly higher in the

210 conventional group compared to the organic one while for the rest of metabolites, no significant

211 difference between groups was detected (Table 3).

212 The molar sums of EPs, MPs and DAPs are presented in Figure 2 and Table 4. While no significant

213 difference in urinary concentrations across groups was observed for total MPs ( $p$-value $=0.47$ ) and total

214 EPs (p-value=0.09), the total DAPs concentration was lower in the organic group compared to the

215 conventional group, with means of 0.29 and $0.41 \mu \mathrm{g} / \mathrm{g}$ creatinine respectively (p-value $=0.03$ ). Some

216 consumers had high exposure levels in both groups as shown by rather different orders of magnitude

217 of means and medians.

218 When the population sample was restricted to pairs using a different criteria, namely $<5 \%$ of organic

219 food in the diet for conventional consumers (instead of $10 \%$ as previously stated) $(\mathrm{n}=218)$, mean 220 difference for total EPs was accentuated and reached statistical significance (Table 5), indicating a 221 possible dose-response relationship.

\section{Discussion}

In this observational study, when comparing urine pesticide metabolites in consumers with discriminant consumption of organic food, significantly higher urinary levels of DETP, DMTP, total DAPs (organophosphorus metabolites) and free 3-PBA (a pyrethroid metabolite) were found among conventional consumers compared to organic consumers, while, overall, low detection rates were found for parent compounds in both groups. In a sensitivity analysis, with conventional consumers with a maximum of $5 \%$ of organic food in their diet, differences between groups were more salient, in particular for EPs. This suggests that organophosphorus and pyrethroid pesticide exposure in adults may be noticeably lowered by introducing organic foods in the diet.

During the last decade, several studies comparing the levels of urine pesticides between "organic" and "conventional" consumers have been conducted in children ${ }^{17-19,38}$ and in adults ${ }^{20,21}$. Beyond disparities in age range and dietary patterns of the populations as well as the periods when they have

235 been conducted, these studies largely differed in their methodology. Most of them were indeed interventional cross-over studies ${ }^{17,19,21,38}$, two were observational ${ }^{18,20}$. An exposure to a wide range of 
metabolites was assessed including organophosphorus pesticide metabolites but also, less frequently, pyrethroids and some herbicides. Studies conducted among children reported reduction in total DAPs ${ }^{17,18}$ or metabolites of malathion and chlorpyrifos ${ }^{19,38}$ after switching to an organic controlled diet or when comparing organic and conventional participants. A drastic and immediate reduction was reported in cross-over studies. For instance, among 40 Mexican-American 3-6 years children, total DAPs reduction was $40 \%$ after 7 days of organic diet ${ }^{17}$. Similarly, in a study conducted among preschool children, mean DMP urinary concentration was 9 times lower among 18 children following an organic diet compared to 21 children eating a conventional one ${ }^{18}$. Overall, these studies argue for a central role of the mode of production of food in organophosphorus pesticide exposure among children. These results were observed even in the study with an observational design reflecting actual levels of organic food consumption ${ }^{18}$.

In the present study conducted in French adults, significant reductions in median urinary concentrations - ranging from $17 \%$ to $55 \%$ - were observed for DETP, DMTP and free 3-PBA in organic consumers compared to conventional consumers while no significant results were found for the other pesticides investigated.

To the best of our knowledge, only one experimental crossover study has been carried out among adults to test for modification in urinary pesticide metabolites following a period of organic diet ${ }^{21}$. In that crossover study conducted among 13 adults in Australia, participants alternated two 7-day periods during which diets were either composed of at least $80 \%$ of conventional foods or organic foods. All DAPs were less frequently detected during the organic period than during the conventional one. After applying the same calculation as in our study for left-censored data, a reduction of $89 \%$ of total DAPs was observed. Indeed, during the organic phase, total DAPs mean concentration was $0.032 \pm 0.038$ $\mu \mathrm{mol} / \mathrm{g}$ creatinine while total DAPs mean concentration among "organic consumers" was $0.29 \pm 0.42$ in our study. During the conventional diet period, total DAPs mean concentration was $0.294 \pm 0.435$ $\mu \mathrm{mol} / \mathrm{g}$ creatinine while we found total DAPs mean concentration of $0.41 \pm 0.64$ among conventional consumers. These differences in the level of exposure may be explained by different designs (experimental vs observational) as well as by different methodological approaches. Indeed, our study is based on observational data, i.e. based on actual self-reported data with participants that did not 
consume $100 \%$ organic or conventional food. In other words, given the cut-off used herein (i.e. minimum $50 \%$ of the diet coming from organic sources) conventional foods could also make up a quite important part of the diet in the "organic group", leading to a certain and variable dietary pesticide exposure. In the same line, our sensitivity analysis data clearly showed that reducing the proportion of organic foods (from maximum $10 \%$ to $5 \%$ ) in the conventional consumer diet exacerbated the differences between groups in some metabolite concentrations. In addition, in our study, the definition of organic consumers was based on data collected using a self-administered food frequency questionnaire covering the past year. Use of a self-administered food frequency questionnaire, prone to some measurement error may have led to misclassification. Moreover, as organophosphorus metabolites exhibit a short half-live ${ }^{39}$, it is possible that some participants identified as organic consumers have consumed highly contaminated (conventional) food just before the urine sampling. As underlined in another study ${ }^{20}$, the very short half live of these compounds may strongly limit the relevance of this type of measure to assess the overall exposure to organophosphorus.

In the only other observational study carried out in adults, urinary DAPs and self-reported organic food consumption habits (using a 3-categories question) were assessed in 480 US participants ${ }^{20}$. In that study, total DAPs concentrations significantly decreased while increasing consumption of organic food with a difference of $65 \%$ between never organic food consumers and often/always organic food consumers. The magnitudes of the effects of switching from conventional to organic diets were comparable to those observed in our study, i.e. lower than in experimental controlled trials.

Herein, total DEAMP, total TBZ-OH, total tebuconazole, most EPs and MPs, and free 3-PBA were frequently detected with rather high levels, even among organic consumers. As already mentioned, this may be explained by the fact that, in so-called high organic food consumers, organic food made up, on average, "only" $63 \%$ of the diet, meaning that, on average, almost $40 \%$ of the food was conventional. These individuals may have also been big consumers of conventional fruit and vegetables, leading to an overall quite high dietary pesticide exposure.

Compared with pesticide exposures estimated in 2006 in a random representative French survey (ENNS), participants of the conventional group in our study exhibited comparable urinary pesticide 
levels for DETP, DMTP and lower for DMDTP ${ }^{40}$. In contrast, mean urinary concentrations of DEP and DMP were markedly higher in our study ${ }^{40}$. For instance, mean and median of DEP urinary concentrations among our conventional group were 31.68 and $0.96 \mu \mathrm{g} / \mathrm{g}$ creatinine while in the ENNS study the respective values were 3.89 and 3.66. These findings reveal extremely different distributions of pesticide exposure levels between the ENNS survey and our study in which some participants had very high exposure levels. These differences can also partly be explained by the different approach used for left-censored data. Concerning pyrethroid metabolites, the median urinary concentration of free 4-F-3-PBA was very low in our study $(\mathrm{LOD}=0.02 \mu \mathrm{g} / \mathrm{L})$, as in the ENNS study $(<\mathrm{LOD}=0.03$ $\mu \mathrm{g} / \mathrm{L}$ ). For 3-PBA, the urinary concentration was higher in the ENNS study with a geometric mean of $0.72 \mu \mathrm{g} / \mathrm{g}$ creatinine which compares to a mean of $0.13 \mu \mathrm{g} / \mathrm{g}$ creatinine in the conventional group of our study. As we mentioned above, it can be hypothesized that since subjects in our sample were very high consumers of fruit, vegetables and whole grains compared to the French population ${ }^{41}$, they must have been particularly exposed to pesticides from plant-based products, which are indeed largely sprayed by synthetic chemicals ${ }^{16}$. This hypothesis is reinforced by the observation that some urinary organophosphorus pesticide metabolites concentrations (namely DETP and DMTP) and 3-PBA are linearly associated with conventional fruit and vegetable consumption (data not shown) in our study. For instance a factor 4 was observed for DETP urinary concentration between $1^{\text {st }}$ and $3^{\text {rd }}$ tertiles of consumption of conventional fruit and vegetables.

Some limitations should be highlighted. First, our study design is entirely observational and based on self-reported data. Thus, consumption data are prone to misestimating, and in particular organic food consumption may have been overestimated ${ }^{31}$. While food consumption data are relatively precisely recorded, we did not quantify the extent of other sources of exposure (i.e. occupational, home or environmental ones). For instance, thiabendazole is not only authorized as a plant protection product but is also a biocide for wood treatment (see Supplemental Table 1). In addition, it is a preservative authorized for use in foodstuffs intended for human consumption (E233), and an anthelminthic drug used in human and veterinary medicine. In this case, the presence of thiabendazole metabolites in urine can be due to multiple non-dietary sources, although it should be born in mind that diet remains the main source of pesticide exposure in the general population. The absence of difference in 
pesticides exposure may also be due to a lack of power, at least for contaminants with very low detection or quantification levels. The use of a middle bound scenario for left-censored data may also have led to the overestimation of some estimates.

Another limit pertains to the efficiency of matching. Although a wide range of confounders were used to estimate the propensity score, we cannot rule out possible residual confounding between organic and conventional consumers. In addition, propensity score matching leads to the exclusion of "particular" subjects unable to be matched, thus avoiding the external validity of findings as previously highlighted ${ }^{33}$. Our study sample, composed of volunteers, was particular with respect to sociodemographic characteristics and dietary intakes and thus is not comparable to the general population. NutriNet-Santé participants have indeed higher intakes of fruit and vegetables than the general French population ${ }^{41}$. Finally, as previously mentioned, concerning urinary DAPs and 3-PBA concentrations, the reliability of such biomarkers to reflect long-term exposure (usual diet, as assessed with the Org-FFQ) is questionable as their half live is short ${ }^{39,42}$ and only one biological sampling has been available. It should also be noted that given most pesticide moieties studied herein were no longer authorized for use in conventional agriculture at the time of urine sampling, the differences in overall pesticide exposure between the two groups of consumers are likely under-estimated.

Our study also exhibits major strengths. Detailed data was used to assess organic and conventional consumption in the overall diet. We used an effective method, i.e. propensity score, allowing to match organic and conventional consumers using a wide range of covariates (including sociodemographic, dietary and health data). Finally, this is the first study conducted in Europe comparing pesticide urinary concentrations from different classes of pesticides, in adults who differed by their organic consumption in real conditions.

\section{Conclusions}

Compared to individuals with low organic food consumption, individuals with high proportion of organic food in their diet had significantly lower levels of various metabolites of pesticides of the organophosphate and pyrethroid families, suggesting that an organic food based-diet may help reduce 
349 the dietary pesticide exposure, at least for some agrochemicals as tested herein. Overall, low detection 350 rates were found for parent compounds in both groups. It also should be stressed that urines of 351 participants in our study displayed rather high exposure levels, irrespective of the group considered, 352 compared to other populations.. It would be also of high interest to conduct similar comparisons in 353 large and representative samples. Accurate assessment of organic food consumption in representative 354 national surveys is therefore required to better evaluate the clinical effects of such differences at the 355 national level. Additional research is also needed to assess the part attributable to dietary pesticide 356 exposure and non-dietary sources as well as the effects of such differences over the long term on 357 health status. 
358 Acknowledgements: We thank all the people who helped carry out the NutriNet-Santé study and all

359 the dedicated and conscientious volunteers. We especially thank Younes Esseddik, Paul Flanzy,

360 Véronique Gourlet, Nathalie Arnault, Fabien Szabo, Laurent Bourhis and Cédric Agaesse.

List of abbreviations:

363

3-PBA, 3-phenoxybenzoic acid;

364 4-F-3-PBA, 4-fluoro-3-phenoxybenzoic acid;

365 CPMO, chlorpyrifos-methyl-oxon;

366 CPO, chlorpyrifos-oxon

367 DAPs, dialkylphosphates;

DEAMP, 2-(diethylamino)-6-methylpyrimidin-4-ol/one;

DEDTP, diethyldithiophosphate;

DEP, diethylphosphate;

371 DETP, diethylthiophosphate;

372 DMDTP, dimethyldithiophosphate;

373 DMP, dimethylphosphate;

374 DMTP, dimethylthiophosphate;

375 ENNS, Etude Nationale Nutrition Santé (French Nutrition and Health Survey)

376 EPs, diethylphosphates;

377 F-PBA, 4-fluoro-3-phenoxybenzoic acid;

378 GC-MS/MS, gas chromatography tandem mass spectrometry;

379 LOD, limit of detection;

380 LOQ, limit of quantification;

381 mPNNS-GS, modified Progamme National Nutrition Santé Guideline Score;

382 MPs, dimethylphosphates;

383 Org-FFQ, organic food frequency questionnaire;

384 PBA, 3-phenoxybenzoic acid;

TBZ-OH, 5-hydroxy-thiabendazole; 
TCP, 3,5,6-trichloropyridinol;

Conflict of Interest: DL acts since 2018 as a scientific expert, with no honoraria or personal funding, in two non-for-profit foundations recently funded in France («Fondation Bjorg, Bonneterre et citoyens » and « Fond de dotation Institut de l'alimentation bio »).

Funding: The BioNutriNet project was supported by the French National Research Agency (Agence Nationale de la Recherche) in the context of the 2013 Programme de Recherche Systèmes Alimentaires Durables (ANR-13-ALID-0001). The NutriNet-Santé cohort study is funded by the following public institutions: Ministère de la Santé, Santé Publique France, Institut National de la Santé et de la Recherche Médicale (INSERM), Institut National de la Recherche Agronomique (INRA), Conservatoire National des Arts et Métiers (CNAM) and Paris 13 University. The funders had no role in study design, data collection and analysis, decision to publish, or preparation of the manuscript.

400

\section{Authors' contributions}

402

The author contributions were as follows: JPC, SH, EKG, DL and PG conceived and designed the experiments. JB performed the experiments. GD and AD performed the urinary dosages. JB and EKG analyzed the data. JB and EKG wrote the paper. All the authors were involved in interpreting results and editing the manuscript. JB and EKG had primary responsibility for final content. All authors read and approved the final manuscript. 


\section{Reference list}

1 Kim K-H, Kabir E, Jahan SA. Exposure to pesticides and the associated human health effects. Sci Total Environ 2017; 575: 525-535.

2 Mostafalou S, Abdollahi M. Pesticides: an update of human exposure and toxicity. Arch Toxicol 2017; 91 : 549-599.

3 Nicolopoulou-Stamati P, Maipas S, Kotampasi C, Stamatis P, Hens L. Chemical Pesticides and Human Health: The Urgent Need for a New Concept in Agriculture. Front Public Health 2016; 4. doi:10.3389/fpubh.2016.00148.

4 Guyton KZ, Loomis D, Grosse Y, El Ghissassi F, Benbrahim-Tallaa L, Guha N et al. Carcinogenicity of tetrachlorvinphos, parathion, malathion, diazinon, and glyphosate. Lancet Oncol 2015; 16: 490-491.

5 Mnif W, Hassine AIH, Bouaziz A, Bartegi A, Thomas O, Roig B. Effect of Endocrine Disruptor Pesticides: A Review. Int J Environ Res Public Health 2011; 8: 2265-2303.

6 Mostafalou S, Abdollahi M. Pesticides and human chronic diseases: evidences, mechanisms, and perspectives. Toxicol Appl Pharmacol 2013; 268: 157-177.

7 Casals-Casas C, Desvergne B. Endocrine Disruptors: From Endocrine to Metabolic Disruption. Annu Rev Physiol 2011; 73: 135-162.

8 Thayer KA, Heindel JJ, Bucher JR, Gallo MA. Role of environmental chemicals in diabetes and obesity: a National Toxicology Program workshop review. Environ Health Perspect 2012; 120: 779.

9 Collectif INSERM. Pesticides : Effets sur la santé, une expertise collective de l'Inserm. Salle Presse Inserm. 2013.http://presse.inserm.fr/pesticides-effets-sur-la-sante-une-expertise-collectivede-linserm/8463/ (accessed 21 Aug2016).

10 Eurostat. Agriculture, forestry and fishery statistics. 2016.

11 Nougadère A, Sirot V, Kadar A, Fastier A, Truchot E, Vergnet C et al. Total diet study on pesticide residues in France: Levels in food as consumed and chronic dietary risk to consumers. Environ Int 2012; 45: 135-150.

12 Union Européenne. Pesticides database. 2016.ec.europa.eu/food/plant/pesticides/eu-pesticidesdatabase/public/.

13 Barański M, Średnicka-Tober D, Volakakis N, Seal C, Sanderson R, Stewart GB et al. Higher antioxidant and lower cadmium concentrations and lower incidence of pesticide residues in organically grown crops: a systematic literature review and meta-analyses. Br J Nutr 2014; : 1-18.

14 Lairon D. Nutritional quality and safety of organic food. A review. Agron Sustain Dev 2010; 30: $33-41$.

15 Smith-Spangler C, Brandeau ML, Hunter GE, Bavinger JC, Pearson M, Eschbach PJ et al. Are Organic Foods Safer or Healthier Than Conventional Alternatives?A Systematic Review. Ann Intern Med 2012; 157: 348-366.

16 Authority (EFSA) EFS. Monitoring data on pesticide residues in food: results on organic versus conventionally produced food. EFSA Support Publ 2018; 15: 1397E. 
17 Bradman A, Quirós-Alcalá L, Castorina R, Aguilar Schall R, Camacho J, Holland NT et al. Effect of Organic Diet Intervention on Pesticide Exposures in Young Children Living in Low-Income Urban and Agricultural Communities. Environ Health Perspect 2015. doi:10.1289/ehp.1408660.

18 Curl CL, Fenske RA, Elgethun K. Organophosphorus Pesticide Exposure of Urban and Suburban Preschool Children with Organic and Conventional Diets. Environ Health Perspect 2002; 111: 377-382.

19 Lu C, Toepel K, Irish R, Fenske RA, Barr DB, Bravo R. Organic Diets Significantly Lower Children's Dietary Exposure to Organophosphorus Pesticides. Environ Health Perspect 2006; 114: $260-263$.

20 Curl CL, Beresford SAA, Fenske RA, Fitzpatrick AL, Lu C, Nettleton JA et al. Estimating Pesticide Exposure from Dietary Intake and Organic Food Choices: The Multi-Ethnic Study of Atherosclerosis (MESA). Environ Health Perspect 2015. doi:10.1289/ehp.1408197.

21 Oates L, Cohen M, Braun L, Schembri A, Taskova R. Reduction in urinary organophosphate pesticide metabolites in adults after a week-long organic diet. Environ Res 2014; 132: 105-111.

22 Agence Bio/CSA. Baromètre de consommation et de perception des produits biologiques en France, 13ème édition.

2016.http://www.agencebio.org/sites/default/files/upload/documents/4_Chiffres/BarometreConso/ 1400610_agence_bio_rapport2015_vp.pdf (accessed 11 Aug2016).

23 Dickson-Spillmann M, Siegrist M, Keller C. Attitudes toward chemicals are associated with preference for natural food. Food Qual Prefer 2011; 22: 149-156.

24 Grunert KG. Food quality and safety: consumer perception and demand. Eur Rev Agric Econ 2005; 32: 369-391.

25 Christine Hoefkens, Wim Verbeke, Joris Aertsens, Koen Mondelaers, John Van Camp. The nutritional and toxicological value of organic vegetables: Consumer perception versus scientific evidence. Br Food J 2009; 111: 1062-1077.

26 Hughner RS, McDonagh P, Prothero A, Shultz CJ, Stanton J. Who are organic food consumers? A compilation and review of why people purchase organic food. J Consum Behav 2007; 6: 94-110.

27 Padilla Bravo C, Cordts A, Schulze B, Spiller A. Assessing determinants of organic food consumption using data from the German National Nutrition Survey II. Food Qual Prefer 2013; 28: $60-70$.

28 Hercberg S, Castetbon K, Czernichow S, Malon A, Mejean C, Kesse E et al. The Nutrinet-Santé Study: a web-based prospective study on the relationship between nutrition and health and determinants of dietary patterns and nutritional status. BMC Public Health 2010; 10: 242.

29 Lassale C, Galan P, Julia C, Fezeu L, Hercberg S, Kesse-Guyot E. Association between Adherence to Nutritional Guidelines, the Metabolic Syndrome and Adiposity Markers in a French Adult General Population. PLoS ONE 2013; 8: e76349.

30 Lassale C, Péneau S, Touvier M, Julia C, Galan P, Hercberg S et al. Validity of web-based selfreported weight and height: results of the Nutrinet-Santé study. J Med Internet Res 2013; 15: e152.

31 Baudry J, Méjean C, Allès B, Péneau S, Touvier M, Hercberg S et al. Contribution of Organic Food to the Diet in a Large Sample of French Adults (the NutriNet-Santé Cohort Study). Nutrients 2015; 7: 8615-8632. 
32 Kesse-Guyot E, Castetbon K, Touvier M, Hercberg S, Galan P. Relative validity and reproducibility of a food frequency questionnaire designed for French adults. Ann Nutr Metab 2010; 57: 153-162.

33 Ali MS, Groenwold RH, Klungel OH. Best (but oft-forgotten) practices: propensity score methods in clinical nutrition research. Am J Clin Nutr 2016; 104: 247-258.

34 Bouatra S, Aziat F, Mandal R, Guo AC, Wilson MR, Knox C et al. The Human Urine Metabolome. PLoS ONE 2013; 8: e73076.

35 GEMS/Food-Euro. Second workshop on reliable evaluation of low-level contamination of food. Report on a workshop in the frame of GEMS/Food-Euro, EUR/HFA target 22. 26-27 May 1995. Kulmbach, German. Geneva: WHO. 1995.

36 Estaquio C, Kesse-Guyot E, Deschamps V, Bertrais S, Dauchet L, Galan P et al. Adherence to the French Programme National Nutrition Santé Guideline Score is associated with better nutrient intake and nutritional status. J Am Diet Assoc 2009; 109: 1031-1041.

37 Baudry J, Allès B, Péneau S, Touvier M, Méjean C, Hercberg S et al. Dietary intakes and diet quality according to levels of organic food consumption by French adults: cross-sectional findings from the NutriNet-Santé Cohort Study. Public Health Nutr 2016; : 1-11.

38 Lu C, Barr DB, Pearson MA, Waller LA. Dietary Intake and Its Contribution to Longitudinal Organophosphorus Pesticide Exposure in Urban/Suburban Children. Environ Health Perspect 2008; 116: 537-542.

39 Griffith W, Curl CL, Fenske RA, Lu CA, Vigoren EM, Faustman EM. Organophosphate pesticide metabolite levels in pre-school children in an agricultural community: Within- and between-child variability in a longitudinal study. Environ Res 2011; 111: 751-756.

40 Fréry N, Saoudi A, Garnier R, Zeghnoun A, Falq G, Guldner L. Exposure of the French population to environmental pollutants-Environmental components of the French National Survey on Nutrition and Health-Initial results. Fr Inst Public Health Surveill St-Maurice Fra 2010.

41 Andreeva VA, Deschamps V, Salanave B, Castetbon K, Verdot C, Kesse-Guyot E et al. Comparison of Dietary Intakes Between a Large Online Cohort Study (Etude NutriNet-Santé) and a Nationally Representative Cross-Sectional Study (Etude Nationale Nutrition Santé) in France: Addressing the Issue of Generalizability in E-Epidemiology. Am J Epidemiol 2016; 184: 660-669.

42 Sudakin DL, Stone DL. Dialkyl phosphates as biomarkers of organophosphates: The current divide between epidemiology and clinical toxicology. Clin Toxicol 2011; 49: 771-781. 
Table 1: Main characteristics of the sample, $n=300$, NutriNet-Santé ${ }^{a}$

\begin{tabular}{|c|c|c|c|}
\hline & Conventional group & Organic group & P-value ${ }^{b}$ \\
\hline $\mathbf{N}$ & 150 & 150 & \\
\hline $\begin{array}{l}\text { Proportion }(\%) \text { of organic food } \\
\text { in the diet }\end{array}$ & $0.03 \pm 0.03$ & $0.67 \pm 0.13$ & $<0.0001^{*}$ \\
\hline Age (y) & $58.71 \pm 12.78$ & $58.35 \pm 11.69$ & 0.60 \\
\hline \% Male & $28 \%$ & $32 \%$ & 0.47 \\
\hline Energy intake (kcal/d) & $1927 \pm 561.3$ & $1994 \pm 601.6$ & 0.37 \\
\hline mPNNS-GS ${ }^{c}$ (13.5) & $8.73 \pm 1.76$ & $8.73 \pm 1.67$ & 0.59 \\
\hline Body mass index $(\mathrm{BMI})\left(\mathrm{kg} / \mathrm{m}^{2}\right)$ & $24.18 \pm 4.11$ & $24.19 \pm 4.02$ & 0.93 \\
\hline Tobacco status (\%) & & & 0.38 \\
\hline never smoker & 48.67 & 47.33 & \\
\hline former smoker & 44 & 40.67 & \\
\hline current smoker & 7.33 & 12 & \\
\hline Physical activity (\%) & & & 0.85 \\
\hline missing & 9 & 8 & \\
\hline low & 17 & 19 & \\
\hline medium & 37 & 35 & \\
\hline high & 37 & 38 & \\
\hline $\begin{array}{l}\text { Vegetarian or vegan diet (yes) } \\
(\%)\end{array}$ & 1.33 & 2 & 0.65 \\
\hline Location (\%) & & & 0.75 \\
\hline rural community & 24 & 25.33 & \\
\hline $\begin{array}{l}\text { urban unit with a population } \\
\text { smaller than } 20000 \text { inhabitants } \\
\text { urban unit with a population }\end{array}$ & 11.33 & 14 & \\
\hline $\begin{array}{l}\text { between } 20000 \text { and } 200000 \\
\text { inhabitants }\end{array}$ & 18.67 & 20.67 & \\
\hline $\begin{array}{l}\text { urban unit with a population } \\
\text { higher than } 200000 \text { inhabitants }\end{array}$ & 46 & 40 & \\
\hline Education (\%) & & & 0.60 \\
\hline$<$ high school diploma & 22 & 22 & \\
\hline high school diploma & 12.67 & 16.67 & \\
\hline$>$ high school diploma & 65.34 & 61.34 & \\
\hline $\begin{array}{l}\text { Monthly income per household } \\
\text { unit }(€) \%\end{array}$ & & & 0.77 \\
\hline refused to declare & 9.33 & 7.33 & \\
\hline $900-1200$ & 6.67 & 8.67 & \\
\hline $1200-1800$ & 22.67 & 20 & \\
\hline $1800-2700$ & 22 & 26.67 & \\
\hline$>2700$ & 39.33 & 37.33 & \\
\hline
\end{tabular}

Abbreviation: mPNNS-GS, modified Programme National Nutrition Santé Guidelines score

${ }^{\mathrm{a}}$ Means $( \pm \mathrm{SD})$ or percentages as appropriate.

${ }^{\mathrm{b}} \mathrm{P}$-values referred to Wilcoxon matched pair signed-rank tests for continuous variables, Mc Nemar's test or conditional logistic regression for categorical variables

${ }^{c} \mathrm{mPNNS}-\mathrm{GS}$ is a dietary index reflecting the level of adherence to French nutritional guidelines

*Significant difference, $\mathrm{p}$-value $<0.05$ 
Table 2: Results for the pesticide parent compounds across organic $(n=150)$ and conventional $(n=150)$ groups, NutriNet-Santé

\begin{tabular}{|c|c|c|c|c|c|c|c|c|c|c|c|}
\hline $\begin{array}{c}\text { Pesticides } \\
(\mu \mathrm{g} / \mathrm{g} \text { creatinine })\end{array}$ & Mean \pm SD & P10 & P50 & P90 & $\begin{array}{c}\text { P- } \\
\text { value }^{\mathrm{a}}\end{array}$ & $\begin{array}{l}\text { LOD } \\
(\mu \mathrm{g} / \mathrm{L})\end{array}$ & $\begin{array}{c}\mathrm{LOQ} \\
(\mu \mathrm{g} / \mathrm{L} \\
)\end{array}$ & $\begin{array}{l}\text { Crude } \\
\text { mean } \\
(\mu \mathrm{g} / \mathrm{L})\end{array}$ & $\begin{array}{l}\text { Crude median } \\
\qquad(\mu \mathrm{g} / \mathrm{L})\end{array}$ & $\begin{array}{c}\% \text { of } \\
\text { detection }\end{array}$ & $\begin{array}{c}\% \text { of } \\
\text { quantificatio } \\
n\end{array}$ \\
\hline Malathion & & & & & 0.09 & 0.003 & 0.01 & & & & \\
\hline Organic group & $0.0083 \pm 0.0321$ & 0.0009 & 0.0020 & 0.0068 & & & & 0.0039 & 0.0015 & 3 & 3 \\
\hline Conventional group & $0.0080 \pm 0.0283$ & 0.0009 & 0.0023 & 0.0116 & & & & 0.0041 & 0.0015 & 9 & 7 \\
\hline Chlorpyrifos & & & & & 0.55 & 0.02 & 0.05 & & & & \\
\hline Organic group & $0.0405 \pm 0.2419$ & 0.0058 & 0.0138 & 0.0420 & & & & 0.0151 & 0.0100 & 3 & 2 \\
\hline Conventional group & $0.0227 \pm 0.0287$ & 0.0056 & 0.0144 & 0.0511 & & & & 0.0103 & 0.0100 & 2 & 0 \\
\hline $\begin{array}{l}\text { Chlorpyrifos- } \\
\text { methyl }\end{array}$ & & & & & 0.45 & 0.2 & 0.5 & & & & \\
\hline Organic group & $0.1886 \pm 0.1520$ & 0.0582 & 0.1350 & 0.3975 & & & & 0.1010 & 0.1000 & 1 & 1 \\
\hline Conventional group & $0.2089 \pm 0.1899$ & 0.0555 & 0.1437 & 0.4858 & & & & 0.100 & 0.1000 & 0 & 0 \\
\hline Phoxim & & & & & 0.65 & 0.05 & 0.1 & & & & \\
\hline Organic group & $0.0510 \pm 0.0439$ & 0.0148 & 0.0348 & 0.1089 & & & & 0.0298 & 0.0250 & 5 & 2 \\
\hline Conventional group & $0.0569 \pm 0.0643$ & 0.0139 & 0.0371 & 0.1246 & & & & 0.0272 & 0.0250 & 3 & 2 \\
\hline Diazinon & & & & & 0.33 & 0.02 & 0.05 & & & & \\
\hline Organic group & $0.0188 \pm 0.0152$ & 0.0058 & 0.0133 & 0.0398 & & & & 0.0100 & 0.0100 & 0 & 0 \\
\hline Conventional group & $0.0277 \pm 0.0654$ & 0.0056 & 0.0144 & 0.0511 & & & & 0.0124 & 0.0100 & 1 & 1 \\
\hline Dichlorvos & & & & & 0.42 & 0.3 & 0.9 & & & & \\
\hline Organic group & $0.2819 \pm 0.2285$ & 0.0873 & 0.1993 & 0.5962 & & & & 0.1500 & 0.1500 & 0 & 0 \\
\hline Conventional group & $0.3134 \pm 0.2849$ & 0.0833 & 0.2156 & 0.7286 & & & & 0.1500 & 0.1500 & 0 & 0 \\
\hline
\end{tabular}

Abbreviations: LOD, Limit of detection; LOQ, Limit of quantification

${ }^{\mathrm{a}} \mathrm{P}$-values referred to Wilcoxon matched pair signed-rank tests 
Table 3: Results for the pesticide metabolites across organic $(n=150)$ and conventional $(n=150)$ groups, NutriNet-Santé

\begin{tabular}{|c|c|c|c|c|c|c|c|c|c|c|c|}
\hline $\begin{array}{c}\text { Pesticides } \\
(\mu \mathrm{g} / \mathrm{g} \text { creatinine })\end{array}$ & Mean \pm SD & P10 & P50 & $\mathrm{P} 90$ & P-value ${ }^{a}$ & $\begin{array}{c}\text { LOD } \\
(\mu \mathrm{g} / \mathrm{L})\end{array}$ & $\begin{array}{c}\mathrm{LOQ} \\
(\mu \mathrm{g} / \mathrm{L}) \\
\end{array}$ & $\begin{array}{c}\text { Crude mean } \\
(\mu \mathrm{g} / \mathrm{L})\end{array}$ & $\begin{array}{c}\text { Crude median } \\
(\mu \mathrm{g} / \mathrm{L})\end{array}$ & $\begin{array}{c}\% \text { of } \\
\text { detection }\end{array}$ & $\begin{array}{c}\% \text { of } \\
\text { quantification }\end{array}$ \\
\hline СРO & & & & & 0.45 & 0.005 & 0.01 & & & & \\
\hline Organic group & $0.0050 \pm 0.0053$ & 0.0015 & 0.0033 & 0.0102 & & & & 0.0026 & 0.0025 & 1 & 1 \\
\hline Conventional group & $0.00548 \pm 0.0062$ & 0.0014 & 0.0036 & 0.0125 & & & & 0.0025 & 0.0025 & 1 & 0 \\
\hline СРMO & & & & & 0.42 & 0.02 & 0.05 & & & & \\
\hline Organic group & $0.0188 \pm 0.0152$ & 0.0058 & 0.0133 & 0.0398 & & & & 0.0100 & 0.0100 & 0 & 0 \\
\hline Conventional group & $0.0209 \pm 0.0190$ & 0.0056 & 0.0144 & 0.0486 & & & & 0.0100 & 0.0100 & 0 & 0 \\
\hline free TCP & & & & & 0.32 & 0.2 & 0.5 & & & & \\
\hline Organic group & $0.1918 \pm 0.1574$ & 0.0582 & 0.1350 & 0.4097 & & & & 0.1020 & 0.1000 & 1 & 0 \\
\hline Conventional group & $0.2254 \pm 0.2337$ & 0.0610 & 0.1485 & 0.5110 & & & & 0.1183 & 0.1000 & 3 & 1 \\
\hline total TCP & & & & & 0.14 & 0.2 & 0.5 & & & & \\
\hline Organic group & $0.3177 \pm 0.4123$ & 0.0590 & 0.1794 & 0.7078 & & & & 0.1804 & 0.1000 & 21 & 8 \\
\hline Conventional group & $0.4155 \pm 0.6757$ & 0.0678 & 0.2029 & 0.7902 & & & & 0.2435 & 0.1000 & 29 & 13 \\
\hline free DEAMP & & & & & 0.46 & 0.03 & 0.1 & & & & \\
\hline Organic group & $0.0404 \pm 0.0620$ & 0.0090 & 0.0237 & 0.0733 & & & & 0.0232 & 0.0150 & 10 & 5 \\
\hline Conventional group & $0.0378 \pm 0.0379$ & 0.0091 & 0.0230 & 0.0798 & & & & 0.0212 & 0.0150 & 8 & 3 \\
\hline total DEAMP & & & & & 0.06 & 0.03 & 0.1 & & & & \\
\hline Organic group & $0.6121 \pm 1.368$ & 0.0115 & 0.1104 & 1.386 & & & & 0.3927 & 0.0500 & 65 & 42 \\
\hline Conventional group & $0.6953 \pm 1.243$ & 0.0151 & 0.2116 & 1.894 & & & & 0.4874 & 0.1400 & 70 & 58 \\
\hline
\end{tabular}




\section{free TBZ-OH}

Organic group

Conventional group

total TBZ-OH

Organic group

Conventional group

\section{free tebuconazole}

Organic group

Conventional group

total tebuconazole

Organic group

Conventional group

\section{DEP}

Organic group

Conventional group

DETP

Organic group

Conventional group

\section{DEDTP}

Organic group

$\begin{array}{llll}0.0339 \pm 0.0445 & 0.0087 & 0.0209 & 0.0654 \\ 0.0336 \pm 0.0315 & 0.0087 & 0.0225 & 0.0767 \\ & & & \\ 0.2762 \pm 0.8386 & 0.0095 & 0.0424 & 0.5728 \\ 0.1635 \pm 0.2193 & 0.0124 & 0.0757 & 0.4165\end{array}$

$0.60 \quad 0.03$

$$
0.26
$$$$
0.03
$$

$\begin{array}{lll}0.0124 & 0.0757 & 0.4165\end{array}$

$$
0.44
$$$$
0.0292 \pm 0.0240
$$

0.0087

0.0206

0.0630

$0.0334 \pm 0.0364$

0.0083

0.0217

0.0748

$0.2859 \pm 0.5257$

$0.2704 \pm 0.5995$

0.0937

0.7685

$\begin{array}{lll}0.0153 & 0.0904 & 0.6416\end{array}$

$$
0.83
$$$$
0.03
$$$$
0.03
$$$$
0.1
$$

0.1

0.6

$$
0.14
$$

$18.61 \pm 42.06$

0.0646

0.6388

55.01

$31.68 \pm 69.38$

0.0684

0.9682

80.96

$$
0.4305 \pm 1.208
$$

0.0623

$1.018 \pm 2.480$

$\begin{array}{lll}0.0758 & 0.2966 \quad 1.966\end{array}$

0.42

$\begin{array}{lll}0.0582 & 0.1329 & 0.3975\end{array}$

$0.0003 * \quad 0.2 \quad 0.6$

0.2775

0.6775

0.6
0.0157

0.0158

0.2554

0.1986

0.0500

0.0500

$\begin{array}{llll}10.61 & 0.1000 & 49 & 48 \\ 15.91 & 0.6800 & 52 & 51\end{array}$

$\begin{array}{lll}0.0181 & 0.0150 & 5 \\ 0.0180 & 0.0150 & 3\end{array}$


Conventional group

DMP

Organic group

Conventional group

DMTP

Organic group

Conventional group

DMDTP

Organic group

Conventional group

free 3-PBA

Organic group

Conventional group

\section{total 3-PBA}

Organic group

Conventional group

free 4-F-3-PBA

Organic group

Conventional group

total 4-F-3-PBA

Organic group
$0.2089 \pm 0.1899$

0.0555

0.1437

0.4858

$$
0.49
$$

$17.85 \pm 35.22$

0.2253

5.427

50.61

$18.66 \pm 45.14$

$0.2171 \quad 3.132$

40.62

$2.654 \pm 6.488$

$6.310 \pm 18.55$

$\begin{array}{lll}0.0894 & 0.6209 & 6.603\end{array}$

$\begin{array}{lll}0.1676 & 1.382 & 13.88\end{array}$

$0.1879 \pm 0.1523$

$0.2212 \pm 0.2080$

$\begin{array}{lll}0.0582 & 0.1329 & 0.3975\end{array}$

$\begin{array}{lll}0.0555 & 0.1437 & 0.5189\end{array}$

$0.001 *$

0.2

0.6

0.25

0.2$$
0.6
$$

4.102

14.30

11.89

2.103

0.1000

0.1053

0.1000

0.1000

$0.03 * \quad 0.02 \quad 0.05$

$\begin{array}{llll}0.0380 \pm 0.0730 & 0.0061 & 0.0171 & 0.0610\end{array}$

$0.0579 \pm 0.1023$

$\begin{array}{lll}0.0068 & 0.0208 \quad 0.1137\end{array}$

0.16

0.02

0.0263

0.0415

0.0100

0.0100

0.05

$0.0885 \pm 0.2877$

$\begin{array}{lll}0.0064 & 0.0201 \quad 0.1798\end{array}$

$0.1301 \pm 0.3536$

0.0076

0.0282

0.3429

0.1178

0.1303

0.0100

0.0100

23

35

18

29

$\begin{array}{lll}0.32 & 0.02 & 0.05\end{array}$

$\begin{array}{llll}0.0191 \pm 0.0154 & 0.0059 & 0.0133 & 0.0410\end{array}$

$0.0222 \pm 0.0221$

$\begin{array}{lll}0.0060 & 0.0149 \quad 0.0499\end{array}$

0.71

0.02

0.05

0.0122

0.0100

0.0100

0

1

0.0123

0.0100

3

2 
Abbreviations: 3-PBA, 3-phenoxybenzoic acid; 4-F-3-PBA, 4-fluoro-3-phenoxybenzoic acid; CPMO, Chlorpyrifos-methyl-oxon; CPO, Chlorpyrifos-oxon;

DAPs, dialkylphosphates; DEAMP， 2-(diethylamino)-6-methylpyrimidin-4-ol/one; DEDTP, diethyldithiophosphate; DEP, diethylphosphate;

DETP, diethylthiophosphate; DMDTP, dimethyldithiophosphate; DMP, dimethylphosphate; DMTP, dimethylthiophosphate; EPs, diethylphosphates; LOD,

Limit of detection; LOQ, Limit of quantification; MPs, dimethylphosphates; TBZ-OH, thiabendazole-5-OH; TCP, 3,5,6- trichloropyridinol

${ }^{\mathrm{a}} \mathrm{P}$-values referred to Wilcoxon matched pair signed-rank tests

*Significant difference, p-value $<0.05$ 
Table 4: Molar sum of DAP metabolites in $\mu \mathrm{mol} / \mathrm{g}$ creatinine organic $(\mathrm{n}=150)$ and conventional $(\mathrm{n}=150)$ groups, NutriNet-Santé ${ }^{\mathrm{a}}$

\begin{tabular}{|c|c|c|c|c|c|}
\hline & Mean \pm SD & $\mathrm{P} 10$ & $\mathrm{P} 50$ & $\mathrm{P} 90$ & $\mathrm{P}$-value ${ }^{\mathrm{b}}$ \\
\hline \multicolumn{6}{|l|}{ total EPs } \\
\hline Organic group & $0.13 \pm 0.28$ & 0.00 & 0.01 & 0.36 & 0.09 \\
\hline Conventional group & $0.21 \pm 0.45$ & 0.00 & 0.02 & 0.54 & \\
\hline total MPs & & & & & 0.47 \\
\hline Organic group & $0.16 \pm 0.29$ & 0.00 & 0.06 & 0.45 & \\
\hline Conventional group & $0.20 \pm 0.39$ & 0.01 & 0.06 & 0.42 & \\
\hline total DAPs & & & & & $0.03 *$ \\
\hline Organic group & $0.29 \pm 0.42$ & 0.01 & 0.12 & 0.82 & \\
\hline Conventional group & $0.41 \pm 0.64$ & 0.01 & 0.16 & 1.23 & \\
\hline
\end{tabular}

Abbreviations: DAPs, dialkylphosphates; EPs, diethylphosphates; MPs, dimethylphosphates

${ }^{a}$ Conventional consumers were defined as individuals with a maximum of $10 \%$ of organic food in their diet

${ }^{b} \mathrm{P}$-values referred to Wilcoxon matched pair signed-rank tests

*Significant difference, $\mathrm{p}$-value $<0.05$ 
Table 5: Molar sum of DAP metabolites in $\mu \mathrm{mol} / \mathrm{g}$ creatinine across organic $(\mathrm{n}=109)$ and conventional $(\mathrm{n}=109)$ groups, NutriNet-Santé ${ }^{\mathrm{a}}$

\begin{tabular}{lccccc}
\hline & Mean $\pm \mathrm{SD}$ & $\mathrm{P} 10$ & $\mathrm{P} 50$ & $\mathrm{P} 90$ & $\mathrm{P}^{\mathrm{b}}$ \\
\hline total EPs & & & & & $0.02^{*}$ \\
$\begin{array}{l}\text { Organic group } \\
\begin{array}{l}\text { Conventional group } \\
\text { total MPs }\end{array}\end{array}$ & $0.11 \pm 0.24$ & 0.00 & 0.01 & 0.37 & \\
$\begin{array}{l}\text { Organic group } \\
\begin{array}{l}\text { Conventional group } \\
\text { total DAPs }\end{array}\end{array}$ & $0.17 \pm 0.51$ & 0.00 & 0.03 & 0.88 & \\
$\begin{array}{l}\text { Organic group } \\
\text { Conventional group }\end{array}$ & $0.28 \pm 0.42$ & 0.00 & 0.06 & 0.43 & \\
\hline
\end{tabular}

Abbreviations: DAPs, dialkylphosphates; EPs, diethylphosphates; MPs, dimethylphosphates

${ }^{\mathrm{a}}$ Compared to data presented in Table 4, the population sample was restricted to pairs with conventional consumers defined as individuals with a maximum of $5 \%$ of organic food in their diet ${ }^{\mathrm{b}} \mathrm{P}$-values referred to Wilcoxon matched pair signed-rank tests

*Significant difference, $\mathrm{p}$-value $<0.05$ 
Figure 1: Selection of the study sample

$\mathrm{n}=33,384$ had completed the organic food questionnaire

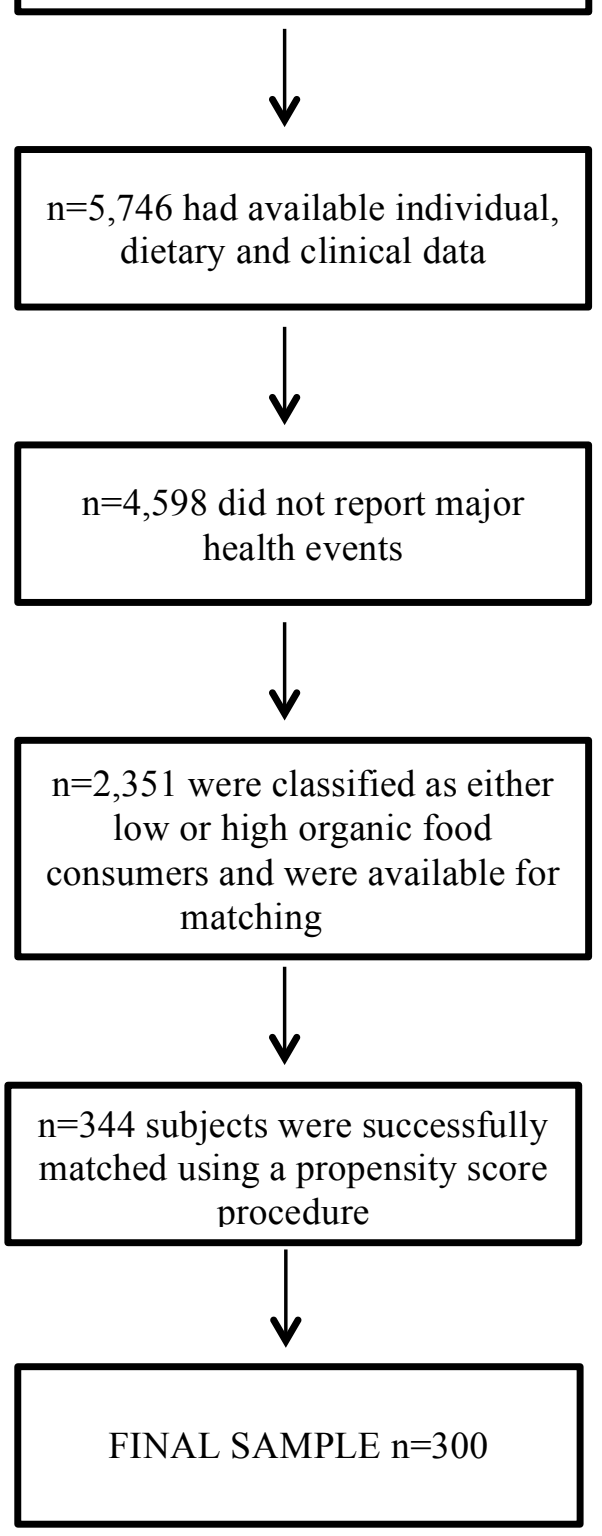


Figure 2: Molar sum of DAP metabolites across organic and conventional groups, $n=300$, NutriNetSanté

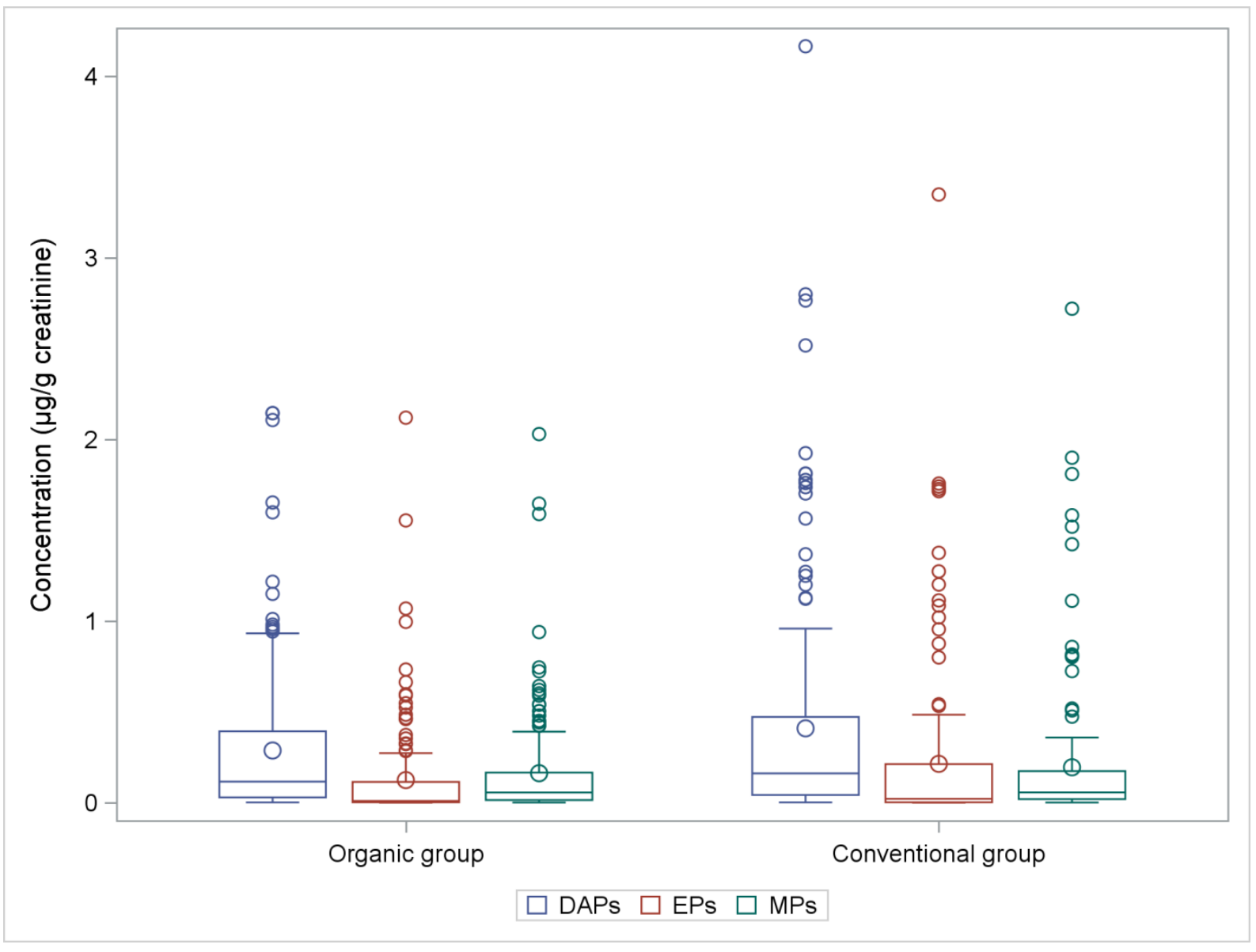

Abbreviations: DAPs, dialkylphosphates; EPs, diethylphosphates; MPs, dimethylphosphates 